\title{
A broadband optical cavity spectrometer for measuring weak near-ultraviolet absorption spectra of gases
}

\author{
J. Chen and D. S. Venables \\ Chemistry Department, University College Cork, Cork, Ireland \\ Environmental Research Institute, University College Cork, Cork, Ireland
}

Received: 21 October 2010 - Published in Atmos. Meas. Tech. Discuss.: 27 October 2010

Revised: 4 February 2011 - Accepted: 16 February 2011 - Published: 1 March 2011

\begin{abstract}
Accurate absorption spectra of gases in the nearultraviolet (300 to $400 \mathrm{~nm}$ ) are essential in atmospheric observations and laboratory studies. This paper describes a novel incoherent broadband cavity-enhanced absorption spectroscopy (IBBCEAS) instrument for measuring very weak absorption spectra from 335 to $375 \mathrm{~nm}$. The instrument performance was validated against the ${ }^{3} \mathrm{~B}_{1}-\mathrm{X}^{1} \mathrm{~A}_{1}$ transition of $\mathrm{SO}_{2}$. The measured absorption varied linearly with $\mathrm{SO}_{2}$ column density and the resulting spectrum agrees well with published spectra. Using the instrument, we report new absorption cross-sections of $\mathrm{O}_{3}$, acetone, 2-butanone, and 2pentanone in this spectral region, where literature data diverge considerably. In the absorption minimum between the Huggins and Chappuis bands, our absorption spectra fall at the lower range of reported ozone absorption crosssections. The spectra of the ketones agree with prior spectra at moderate absorptions, but differ significantly at the limits of other instruments' sensitivity. The collision-induced absorption of the $\mathrm{O}_{4}$ dimer at $360.5 \mathrm{~nm}$ was also measured and found to have a maximum cross-section of ca. $4.0 \times$ $10^{-46} \mathrm{~cm}^{5}$ molecule ${ }^{-2}$. We demonstrate the application of the instrument to quantifying low concentrations of the shortlived radical, $\mathrm{BrO}$, in the presence of stronger absorptions from $\mathrm{Br}_{2}$ and $\mathrm{O}_{3}$.
\end{abstract}

\section{Introduction}

Whereas large absorption cross-sections of atmospheric species are generally well established, weak absorption spectra are often poorly known. Accurate absorption crosssections are important in atmospheric observations, labora-

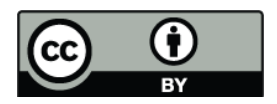

Correspondence to: D. S. Venables (d.venables@ucc.ie) tory work, and studies of fundamental molecular properties. The near-ultraviolet ( $300 \mathrm{~nm}$ to $400 \mathrm{~nm}$ ) absorption spectra of gases are particularly relevant for understanding and modelling the chemistry of the atmosphere, since light in this spectral region drives most tropospheric photochemistry.

Weak absorptions, which occur when molecular absorption cross-sections are small or when the concentration of the species of interest is low, are a challenge to measure. In ozone, for instance, the absolute absorption cross-section drops to about $10^{-23} \mathrm{~cm}^{2}$ molecule ${ }^{-1}$ between the Chappuis and the Huggins bands (around $370 \mathrm{~nm}$ ). Despite its prominent role in atmospheric chemistry, even recent $\mathrm{O}_{3}$ absorption cross-sections differ by almost an order of magnitude in this region (Brion et al., 1998; Bogumil et al., 2003; Voigt et al., 2001). The low concentrations associated with short-lived species also result in weak absorption. Bromine monoxide, $\mathrm{BrO}$, exemplifies this case: although the absorption cross-section of $\mathrm{BrO}$ is large (about $1.5 \times 10^{-17} \mathrm{~cm}^{2}$ molecule ${ }^{-1}$ at $338.5 \mathrm{~nm}$ ) (Fleischmann et al., 2004), the tropospheric mixing ratio is typically only a few ppt (Honninger and Platt, 2002; Peters et al., 2005; Wagner et al., 2007; Mahajan et al., 2009). At a high atmospheric concentration of $10 \mathrm{pptv}$, the maximum absorption of $\mathrm{BrO}$ would be only about $4 \times 10^{-9} \mathrm{~cm}^{-1}$, making it extremely difficult to measure. Even in the laboratory, low concentrations of $\mathrm{BrO}$ are inevitable owing to its fast self-reaction (Fleischmann et al., 2004). Lastly, low gas concentrations are found also for substances with low vapour pressures; as a result, the ultraviolet spectra of many low volatility organic species of atmospheric interest have yet to be determined. This includes the large group of compounds with carbonyl or nitro functional groups, for which the $n \rightarrow \pi$ transition occurs in the near-ultraviolet.

The pathlength of light through the sample primarily determines the spectral quality for weak absorptions. Long pathlengths result in larger, more easily measured absorptions

Published by Copernicus Publications on behalf of the European Geosciences Union. 
according to the Beer-Lambert law. Extensive measurement times are required if the pathlength through the sample is relatively short (on the order of metres, say) which imposes stringent conditions on the stability of both the chemical source and the spectrometer during the measurement. Multipass cells can extend the pathlength from hundreds of metres to a few kilometres, but require large sample volumes (Steyert et al., 2001). Optical cavities provide an alternative means of obtaining a long effective pathlength of light (typically several kilometres) through the sample, and techniques exploiting this property include cavity ring-down spectroscopy and cavity-enhanced absorption spectroscopy (Mazurenka et al., 2005). Such laser-based techniques are exceptionally sensitive to weak absorptions $\left(10^{-9} \mathrm{~cm}^{-1}\right.$ or better) but have some drawbacks for recording broad spectra. Because the laser must be scanned across the spectrum, the approach is limited by the stability of the absorber concentration over the duration of the measurement. Furthermore, the intrinsic high resolution of laser is compromised if measurements are taken at widely spaced intervals, as is sometimes the case (Xiang et al., 2009). The cost and experimental complexity of ultraviolet tuneable laser systems may also be prohibitive.

The simultaneous measurement of a broad spectral window across the long effective pathlength of an optical cavity would be convenient for measuring weak absorption spectra. A method combining these criteria is Incoherent Broadband Cavity-Enhanced Absorption Spectroscopy (IBBCEAS), first demonstrated by Fiedler and co-workers (Fiedler et al., 2003). IBBCEAS employs an optical cavity, a broadband light source (usually a Xe arc lamp or light emitting diode), and a spectrograph to cover a relatively broad spectral window with high sensitivity to weak absorptions (or other extinction processes) in the sample. The technique has proved valuable for quantifying trace gases and aerosol extinction in chamber and field measurements (Venables et al., 2006; Dixneuf et al., 2009; Ball et al., 2010; Varma et al., 2009; Thalman and Volkamer, 2010; Washenfelder et al., 2008) and good agreement with other techniques has been demonstrated in recent intercomparisons of $\mathrm{NO}_{2}$ and $\mathrm{NO}_{3}$ measurements (Dorn et al., 2011; Fuchs et al., 2010). Most IBBCEAS measurements thus far have been at visible wavelengths, with the shortest wavelength measurements between $360 \mathrm{~nm}$ and $380 \mathrm{~nm}$ to quantify $\mathrm{HONO}$ and $\mathrm{NO}_{2}$ (Gherman et al., 2008). To our knowledge, however, the technique has not been employed to record high quality reference spectra.

Our aim in this paper is to demonstrate an IBBCEAS instrument for measuring weak absorption spectra of gases over the wavelength range 335 to $375 \mathrm{~nm}$. We do so by first showing the comparability of $\mathrm{SO}_{2}$ absorption spectra measured by the instrument with literature spectra. The technique is then applied to obtain moderate resolution spectra of several molecules for which the absorption cross-section is poorly constrained in this spectral region, namely ozone, the $\mathrm{O}_{4}$ dimer, and the small ketones acetone, 2-butanone, and 2-pentanone. Moreover, as weak absorption spectra are often used to quantify sample constituents, we also demonstrate the retrieval of the short-lived species $\mathrm{BrO}$ from a background of $\mathrm{Br}_{2}$ and $\mathrm{O}_{3}$.

\section{Experimental section}

\subsection{Spectrometer setup}

The IBBCEAS system is shown schematically in Fig. 1. Light from a $75 \mathrm{~W}$ arc Xe lamp was focused into the centre of a $198 \mathrm{~cm}$ long optical cavity formed by two high reflectivity dielectric mirrors (Layertec). The mirrors had a maximum reflectivity of ca. $99.8 \%$ at $365 \mathrm{~nm}$ and a $5 \mathrm{~m}$ radius of curvature. Focusing the beam into the cavity centre improved the cavity quality and minimised dispersion losses (Fiedler et al., 2007; Wu et al., 2008). Light exiting the cavity was focussed into a Czerny-Turner spectrograph (Andor SR-163) with a $163 \mathrm{~cm}$ focal length and a $12001 \mathrm{~mm}^{-1}$, $300 \mathrm{~nm}$ blaze grating. The spectrum was recorded using a back-illuminated CCD (Andor 420A-BU) optimized for the near-UV and cooled to $-40^{\circ} \mathrm{C}$ to reduce the dark current. The wavelength scale of the spectrograph was calibrated by fitting several emission lines of a $\mathrm{Hg} / \mathrm{Ne}$ lamp to a secondorder polynomial function. The uncertainty of the wavelength calibration was about $0.02 \mathrm{~nm}$ and the average resolution was $0.31 \mathrm{~nm}(25 \mu \mathrm{m}$ slit width $)$ and $0.55 \mathrm{~nm}(100 \mu \mathrm{m}$ slit width) as determined from emission lines at $334 \mathrm{~nm}$ and $365 \mathrm{~nm}$. The lamp output was highly stable: the short term intensity fluctuation of $1 \mathrm{~s}$ duration scans was below $0.1 \%$ and dimming of around $0.4 \%$ was observed over a $2 \mathrm{~h}$ period.

One of the practical challenges with IBBCEAS systems employing Xe arc lamps is to filter the extremely broadband light $(200 \mathrm{~nm}$ to $2000 \mathrm{~nm})$ to the high reflectivity region of the cavity mirrors. The cavity mirrors act as a band rejection filter but longer and shorter wavelengths are efficiently transmitted into the spectrograph, thereby adding to the background signal. A Schott UG11 band pass filter (270 to $380 \mathrm{~nm}$ ) removed most visible and near-IR light in our system, while a heat-absorbing filter (Schott KG1) rejected wavelengths above $900 \mathrm{~nm}$. A final band-pass filter (Semrock FF01-357/44-25) placed in front of the spectrograph provided a final, close match of the filter transmission to the high reflectivity range of the cavity mirrors and a usable spectral region from $335 \mathrm{~nm}$ to $375 \mathrm{~nm}$.

The concentration of absorber must be known to calculate the absorption cross-section. Although any analytical method could be used to quantify the concentrations of $\mathrm{O}_{3}$ and the ketones, here we exploit the single-pass absorption at $320.1 \mathrm{~nm}$ to determine the concentration of the absorber. At this wavelength, which falls outside of the high reflectivity region of the optical cavity mirrors, most light traverses the sample once (a pathlength of $2 \mathrm{~m}$ ). In contrast, the spectrometer is dramatically more sensitive between 335 and $375 \mathrm{~nm}$ 


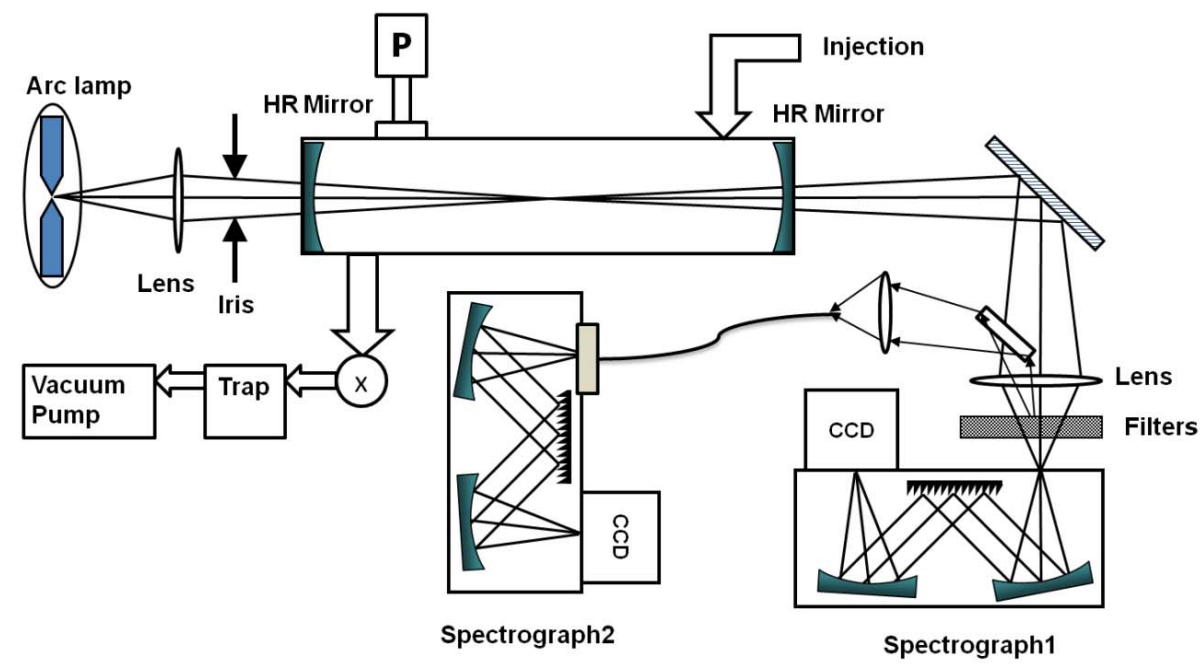

Fig. 1. Schematic diagram of the IBBCEAS instrument. Spectrograph 1 recorded the IBBCEAS spectra, while spectrograph 2 recorded single-pass spectra outside of the cavity mirror reflectivity range.

where the reflectivity is at a maximum and the effective pathlength of light is about $0.5 \mathrm{~km}$. (The effective pathlength in the absence of sample extinction is given by $d /(1-R)$, where $d$ is the mirror separation and $R$ is the mirror reflectivity). The IBBCEAS measurement is therefore about two orders of magnitude more sensitive than the $320 \mathrm{~nm}$ (singlepass) measurement. These species have moderate absorption cross-sections $\left(10^{-20} \mathrm{~cm}^{2}\right.$ molecule $\left.{ }^{-1}\right)$ at $320 \mathrm{~nm}$ and literature spectra agree closely (Meyrahn et al., 1986; Hynes et al., 1992; Martinez et al., 1992; Brion et al., 1998; Gierczak et al., 1998; Burrows et al., 1999; Mu and Mellouki, 2000; Wollenhaupt et al., 2000; Voigt et al., 2001; Bogumil et al., 2003). The absorption was determined by measuring a small portion of the light reflected by the Semrock filter, transmitted through an Andover $320 \mathrm{~nm}$ band-pass filter, and recorded in another spectrograph (Andor SR-303). As the cavity mirrors have a reflectivity of $42 \%$ at $320 \mathrm{~nm}$ (as measured in a UV-visible spectrometer), about $20 \%$ of the light makes two or more passes through the sample. To account for multiple passes, the absorption coefficient was therefore determined from the general cavity equation, Eq. (4), in Fiedler et al. (2003).

The sample cell and optical cavity were enclosed in a vacuum tight system with the middle of the cell enclosed by a $100 \mathrm{~cm}$ glass tube. The outlet was connected to a foreline trap and rotary vane pump. The system pressure was monitored with a Leybold CTR 90 capacitance manometer and samples were studied at atmospheric pressure (ca. $1013 \mathrm{mbar}$ ) and under moderate vacuum. Acetone (Aldrich 99.9\%), 2-pentanone (Aldrich 99\%), 2-butanone (Aldrich 99\%), bromine (Aldrich reagent grade) and $\mathrm{SO}_{2}$ (BOC 99.9\%) were used as received. Samples were introduced into the chamber at well-defined flow rates via MKS mass flow controllers. $\mathrm{Br}_{2}$ and the ketones were introduced into a stream of $\mathrm{N}_{2}$ via a trap assembly. To reduce the $\mathrm{Br}_{2}$ concentration to below $10^{-13} \mathrm{~cm}^{-3}$, the trap was cooled to around $-30^{\circ} \mathrm{C}$ in an alcohol/liquid nitrogen cooling bath and the $\mathrm{Br}_{2} / \mathrm{N}_{2}$ stream diluted further in a higher flow-rate $\mathrm{N}_{2}$ stream. Ozone was produced in a flow of oxygen by an ozone generator (OzoneLab OL80W).

\subsection{Mirror calibration}

The extinction (or absorption) spectrum of a sample in the cavity is given by (Fiedler et al., 2003):

$\varepsilon(\lambda)=\sum_{i} \sigma_{i}(\lambda) \cdot N_{i}=\frac{1}{d}\left(\frac{I_{0}(\lambda)}{I(\lambda)}-1\right)(1-R(\lambda))$

where $I$ and $I_{0}$ are, respectively, the intensities transmitted through the optical cavity in the presence and absence of an absorber, $d$ is the distance between the cavity mirrors, $R$ is the mirror reflectivity, and $\sigma_{i}\left(\mathrm{~cm}^{2}\right.$ molecule $\left.{ }^{-1}\right)$ and $N_{i}$ (molecules $\mathrm{cm}^{-3}$ ) are the absolute absorption cross section and number density of species $i$. Equation (1) implies that the lamp intensity must be stable between the measurement of $I_{0}$ and $I$, and that the mirror reflectivity is known. The reflectivity spectrum of the mirrors was calibrated in two steps. In the first step, the shape of the reflectivity spectrum was determined based on the difference in Rayleigh scattering of $\mathrm{N}_{2}$ and $\mathrm{CO}_{2}$. The cavity was successively flushed with $\mathrm{CO}_{2}$ and $\mathrm{N}_{2}$ at about $1 \mathrm{~L} \mathrm{~min}^{-1}$ for an hour each until the transmitted intensity attained a stable value. The sample was at 1013 mbar and $293 \mathrm{~K}$. The observed extinction, $\varepsilon_{i}$, arising from Rayleigh scattering of gas $i$ is related to the mirror reflectivity according to:

$\alpha_{i}(\lambda)=N_{i} \sigma_{i}^{\text {Rayl }}(\lambda)=\left(\frac{I_{0}(\lambda)}{I_{i}(\lambda)}-1\right) \frac{(1-R(\lambda))}{d}$ 

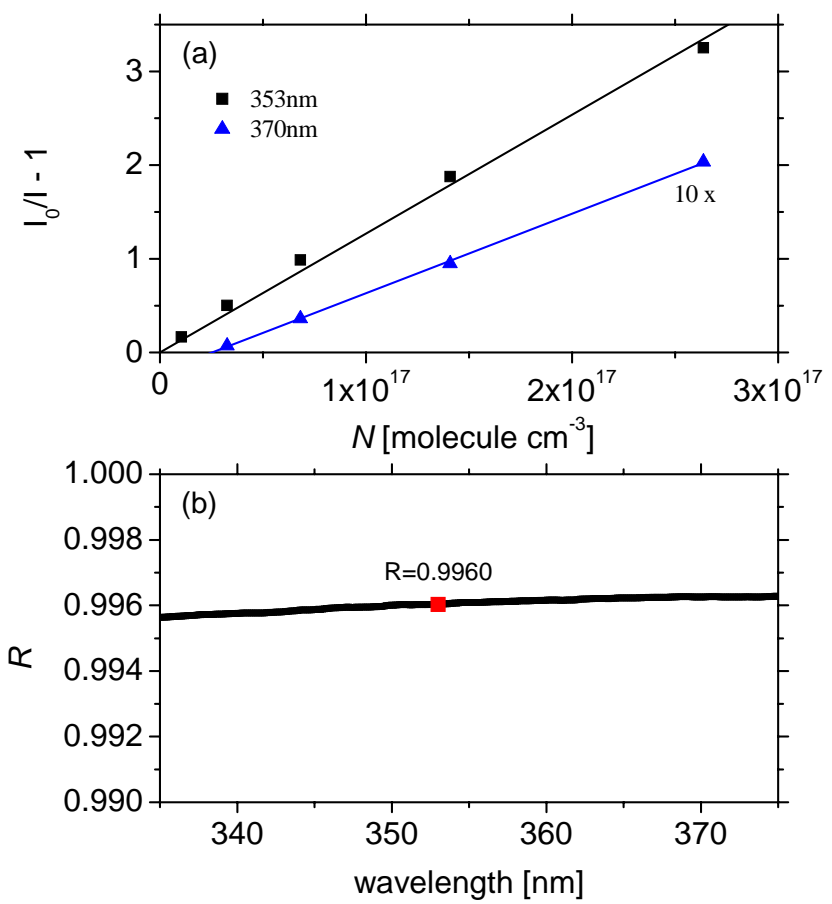

Fig. 2. (a) Fractional absorption of $\mathrm{O}_{3}$ at $353 \mathrm{~nm}$ and $370 \mathrm{~nm}$. The slope of the graph, $\sigma_{\mathrm{O} 3} d /(1-R)$, was used to determine $R$ based on the literature absorption cross-section at $353 \mathrm{~nm}$. (b) Mirror reflectivity scaled to give the literature cross-section of $\mathrm{O}_{3}$ absorption at $353 \mathrm{~nm}$.

In Eq. (2), $I_{0}$ represents the (unmeasured) intensity of a non-scattering medium (that is, equivalent to the evacuated cavity) and $\sigma^{\text {Rayl }}$ is the Rayleigh scattering cross-section of species $i$. Rayleigh scattering cross-sections were based on Naus and Ubachs (2000), Sneep and Ubachs (2005), Sutton and Driscoll (2004). The mirror reflectivity is thus related to the measured intensity through both $\mathrm{CO}_{2}$ and $\mathrm{N}_{2}$ by:

$\frac{(1-R(\lambda))}{d}=\frac{I_{\mathrm{N}_{2}}(\lambda) N_{\mathrm{N}_{2}} \sigma_{N_{2}}^{\text {rayl }}(\lambda)-I_{\mathrm{CO}_{2}}(\lambda) N_{\mathrm{CO}_{2}} \sigma_{\mathrm{CO}_{2}}^{\text {rayl }}(\lambda)}{I_{\mathrm{CO}_{2}}(\lambda)-I_{\mathrm{N}_{2}}(\lambda)}(3)$

Although Rayleigh scattering gives a smooth mirror reflectivity spectrum (Fig. 2b), the relatively small extinction can be susceptible to drifts in lamp intensity, thereby introducing a systematic error. The second step of the mirror calibration therefore scaled the reflectivity to match the absorption of $\mathrm{O}_{3}$ in the cavity to the literature absorption cross-section at $353 \mathrm{~nm}$. The cross-section used was the average of four literature cross-sections convoluted to our instrumental function (Brion et al., 1998; Burrows et al., 1999; Voigt et al., 2001; Bogumil et al., 2003). Figure 2a shows the linear dependence of the fractional absorption with $\mathrm{O}_{3}$ concentration, where the slope equals $\sigma_{\mathrm{O} 3} d /(1-R)$, as indicated by Eq. (1). The scaled mirror reflectivity is rather flat over this spectral range (Fig. 2b). The accuracy of the mirror calibration at $353 \mathrm{~nm}$ is limited by the $7 \%$ standard deviation of the cross-sections at $353 \mathrm{~nm}$, as well as the uncertainty in the individual cross-sections and the regression slope. The uncertainty in the reflectivity at other wavelengths is expected to be somewhat higher further away from $353 \mathrm{~nm}$ but cannot be explicitly quantified. Nevertheless, spectra generally agree closely with literature spectra, with some suggestion of a small overestimation of the mirror reflectivity below $340 \mathrm{~nm}$ in the ketone spectra.

\subsection{Uncertainty of cross-sections}

The uncertainty of the absorption cross-sections was estimated using standard uncertainty propagation. The uncertainty in the extinction coefficient, $\Delta \varepsilon$, was common to all spectra and was evaluated from Eq. (1):

$$
\begin{aligned}
\Delta \varepsilon^{2} & =\left|\frac{\partial \varepsilon}{\partial d}\right|^{2} \Delta d^{2}+\left|\frac{\partial \varepsilon}{\partial(1-R)}\right|^{2} \Delta(1-R)^{2}+\left|\frac{\partial \varepsilon}{\partial I_{0}}\right|^{2} \Delta I_{0}^{2} \\
& =\varepsilon^{2}\left(\frac{\Delta d}{d}\right)^{2}+\varepsilon^{2}\left(\frac{\Delta(1-R)}{1-R}\right)^{2}+\left(\frac{1-R}{d}\right)^{2}\left(\frac{\Delta I_{0}}{I}\right)^{2}
\end{aligned}
$$

where $\Delta d, \Delta(1-R)$, and $\Delta I_{0}$ are the uncertainties in the mirror separation, the mirror reflectivity term, and the intensity. Here $(1-R)$ and $d$ are systematic sources of uncertainty, whereas the intensity term contributes randomly to the final uncertainty. The relative uncertainties in Eq. (4) are $7 \%$ for $(1-R)$ at $353 \mathrm{~nm}, 0.5 \%$ for $d$, and less than $1 \%$ for short-term intensity fluctuations. The overall uncertainty in the extinction measurement at $353 \mathrm{~nm}$ is therefore around $7 \%$ and is clearly dominated by the uncertainty in the mirror, reflectivity. However, the characterisation of the lamp intensity appears to understate the longer-term drift in the intensity, as seen in the small offset at long wavelengths in the spectra of 2-butanone and 2-pentanone (where the absorption is expected to be effectively zero). On the basis of this evidence, the intensity contribution to the uncertainty is estimated to be around $5 \times 10^{-7} \mathrm{~cm}^{-1}$.

The uncertainty in the absorption cross-sections must furthermore account for the uncertainty in the concentration of each species $(\Delta N)$ :

$\left(\frac{\Delta \sigma}{\sigma}\right)^{2}=\left(\frac{\Delta \varepsilon}{\varepsilon}\right)^{2}+\left(\frac{\Delta N}{N}\right)^{2}$

We have estimated $\Delta N$ from the standard deviation of the literature cross-sections at $320 \mathrm{~nm}$ (Table 1), together with a $1.1 \%$ uncertainty in the single-pass absorption measurement. The uncertainties in the concentrations are $3 \%$ for $\mathrm{O}_{3}$, $4 \%$ for acetone, $3 \%$ for 2-butanone and $3 \%$ for 2 -pentanone. The overall uncertainties in absorption cross-sections are thus $8 \%\left(\mathrm{O}_{3}\right), 8 \%$ (acetone), 10\% (2-butanone) and 8\% (2pentanone).

We emphasize that this uncertainty applies to the absorption cross-section at $353 \mathrm{~nm}$ and is necessarily a lower limit. The uncertainty is larger at other wavelengths, and particularly at the long and short wavelength limits of the IBBCEAS spectrum. The uncertainty will therefore be revisited in the 
Table 1. Instrumental parameters of literature absorption cross sections.

\begin{tabular}{lccc}
\hline Author (year) & Temp. [K] & Wavelength [nm] & Resolution [nm] \\
\hline \multicolumn{4}{c}{ Sulfur dioxide } \\
\hline Bogumil et al. (2003) & 293 & $239-395$ & 0.26 \\
Vandaele et al. (2009) & 298 & $227-420$ & 0.03 \\
\hline \multicolumn{4}{c}{ Ozone } \\
\hline Bogumil et al. (2003) & 293 & $230-1075$ & 0.26 \\
Voigt et al. (2001) & 293 & $230-851$ & 0.027 \\
Burrows et al. (1999) & 293 & $230-794$ & $0.2-0.4$ \\
Brion et al. (1998) & 295 & $350-830$ & 0.01 \\
\hline \multicolumn{4}{c}{ Acetone } \\
\hline Yujing et al. (2000) & 298 & $240-350$ & 0.04 \\
Wollenhaupt et al. (2000) & 296 & $220-346$ & 0.16 \\
Gierczak et al. (1998) & 298 & $215-349$ & 0.5 \\
Martinez et al. (1992) & 300 & $202-355$ & 0.5 \\
Hynes et al. (1992) & 298 & $253.7-360$ & 1.8 \\
Meyrahn et al. (1986) & 298 & $275-368$ & 0.07 \\
\hline & $2-B u t a n o n e$ \\
\hline Yujing et al. (2000) & 298 & $240-350$ & 0.04 \\
Martinez et al. (1992) & 300 & $202-355$ & 0.5 \\
\hline & $2-P e n t a n o n e$ \\
\hline Morowitz et al. (1999) & 298 & $210-360$ & \\
\hline
\end{tabular}

Discussion section to place a more conservative estimate on the overall uncertainty in the absorption cross-section.

\section{Results}

\subsection{Sulfur dioxide absorption}

$\mathrm{SO}_{2}$ has a relatively weak absorption band from 345 to $420 \mathrm{~nm}$ arising from the spin-forbidden $\mathrm{a}^{3} \mathrm{~B}_{1}-\mathrm{X}^{1} \mathrm{~A}_{1}$ transition. Since recent spectra agree closely (Vandaele et al., 2009; Bogumil et al., 2003) and because $\mathrm{SO}_{2}$ is stable and easily handled, the absorption of $\mathrm{SO}_{2}$ in this region served as a convenient test of the spectrometer performance.

$\mathrm{SO}_{2}$ was introduced into the spectrometer from a $500 \mu \mathrm{L}$ gas-tight syringe into a stream of $\mathrm{N}_{2}\left(0.5 \mathrm{~L} \mathrm{~min}^{-1}\right)$ at ambient temperature $(296 \mathrm{~K})$ and pressure $(1013 \mathrm{mbar})$. The $\mathrm{SO}_{2}$ flowed through the optical cavity as a short plug of gas with a relatively constant total column density. The sample absorption rose to a maximum for a short period before subsiding as the $\mathrm{SO}_{2}$ was flushed from the chamber. Diffusion of gas into the dead volumes near the cavities mirrors resulted in a relatively long residence time of about $6 \mathrm{~min}$. Measurements were based on the maximum absorption in the cell. The inte- grated absorption from 350 to $375 \mathrm{~nm}$ increased linearly with volume of $\mathrm{SO}_{2}$ (Fig. 3a). The small, negative intercept may have arisen from residual $\mathrm{SO}_{2}$ in the chamber from one injection to another. Repeatability was good, with a standard deviation of $5 \%$ at the absorption peak at $370.2 \mathrm{~nm}$ found for five successive injections of $500 \mu \mathrm{L} \mathrm{SO}_{2}$ (Fig. 3b).

The average absorption cross-section of $\mathrm{SO}_{2}$ from the five samples is shown in Fig. 4. The number density was calculated from the volume of the $\mathrm{SO}_{2}$ injected and the volume of the sample cell. Figure 4 also displays the spectra of Bogumil et al. (2003) and Vandaele et al. (2009) at resolutions of $0.26 \mathrm{~nm}$ and $0.032 \mathrm{~nm}$, respectively, as well as magnitudes of the absorption maxima convoluted to our instrument resolution. The magnitudes of the five largest absorption features above $350 \mathrm{~nm}$ were $28 \%$ larger than the average literature cross-sections, although around half of the difference $\left(8.2 \times 10^{-23} \mathrm{~cm}^{2}\right.$ average) can be explained by our generally higher baseline $\left(4.2 \times 10^{-23} \mathrm{~cm}^{2}\right.$ higher on average $)$. Nevertheless, the agreement between the spectrum reported here and the literature spectra is generally good over this region, which includes changes in absorption coefficient of about an order of magnitude. Together with the absorption linearity and repeatability, these data thus provide evidence of the reliability of the spectra reported here. 

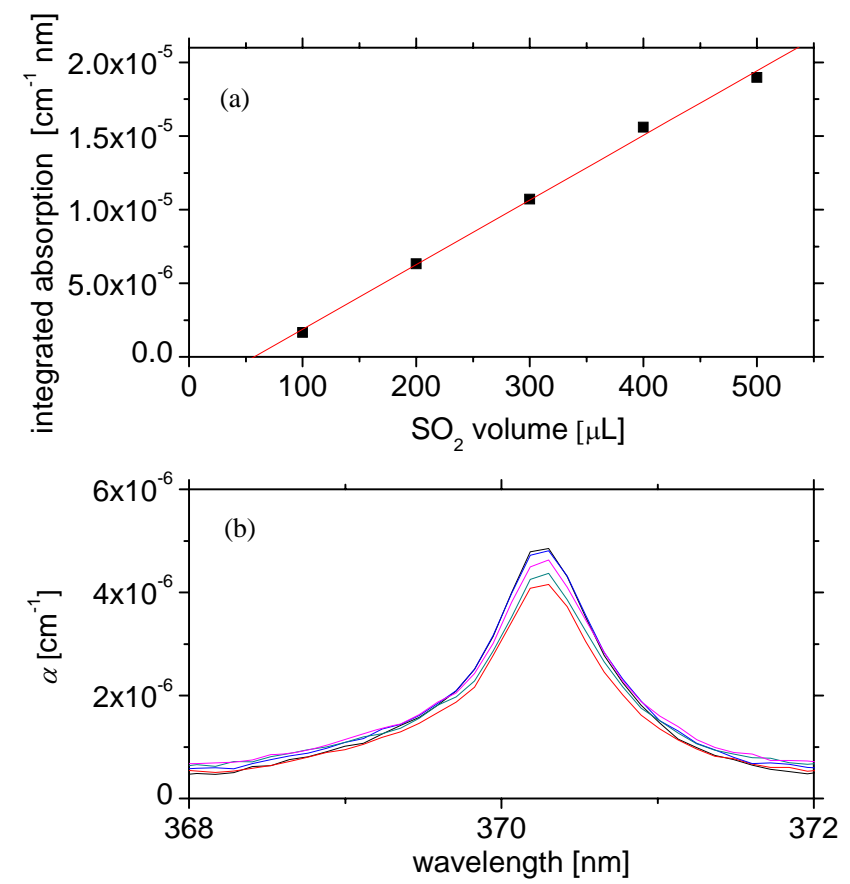

Fig. 3. (a) Dependence of the $\mathrm{SO}_{2}$ integrated absorption on the volume of $\mathrm{SO}_{2}$ introduced into the inlet stream. The correlation coefficient of the linear regression is $R^{2}=0.9961$. (b) Repeatability of five successive injections of $500 \mu \mathrm{L} \mathrm{SO}$ into the inlet stream. The standard deviation is $5 \%$ at the absorption peak at $370.2 \mathrm{~nm}$.

A comparison of the experimental parameters illustrates the sensitivity of our instrument. The $\mathrm{SO}_{2}$ mole fraction of the sample gas is about $0.039 \%$ in our spectrometer compared to pure $\mathrm{SO}_{2}$ and $1 \% \mathrm{SO}_{2}$ in $\mathrm{N}_{2}$ of Vandaele and Bogumil, respectively. Furthermore, the total measurement of $360 \mathrm{~s}$ for the averaged spectra (including the measurement of $\left.I_{0}\right)$ was similar to that of the Bogumil spectra ( $\left.320 \mathrm{~s}\right)$, but much shorter than the acquisition time of ca. $1 \mathrm{~h}$ that Vandaele and co-workers used for several pressure measurements. On the other hand, the lower resolution of our instrument would tend to improve our signal-to-noise over the much higher resolution of the Vandaele and Bogumil spectra. Despite these differences, the noise apparent in the absorption minima is comparable to or smaller than that in the literature spectra.

This absorption band of $\mathrm{SO}_{2}$ has some practical potential. The structured absorption features in this region have recently been used in DOAS measurements of $\mathrm{SO}_{2}$ column densities (Bobrowski et al., 2010). For a broadband optical cavity spectrometer like ours, injection of small volumes of $\mathrm{SO}_{2}$ would also be a convenient approach to calibrate mirror reflectivities since the small absorption cross-section results in moderate, easily measurable absorptions. Strongly absorbing gases such as $\mathrm{NO}_{2}$ must be highly diluted to low levels or no light will be transmitted through the optical cavity.

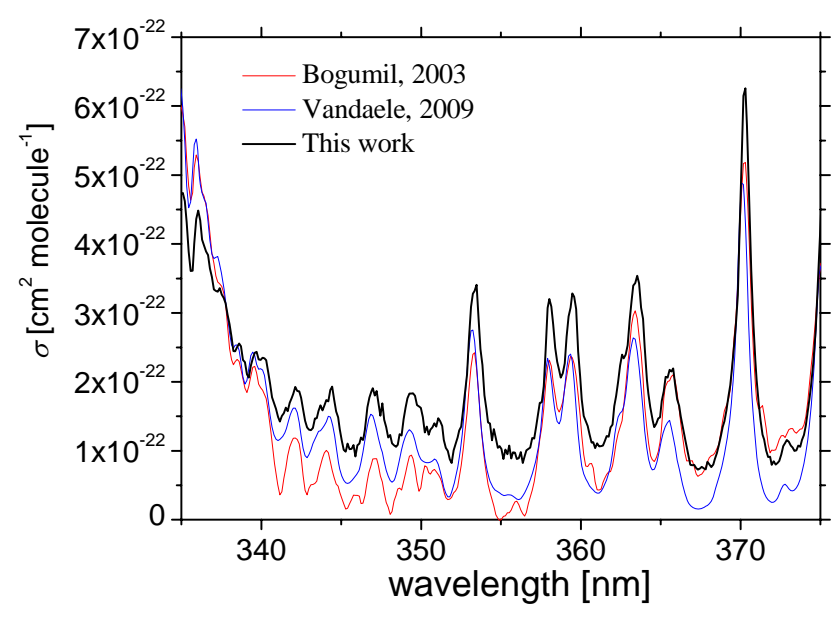

Fig. 4. $\mathrm{SO}_{2}$ absorption cross-sections spectra from this work (black), Bogumil (red) and Vandaele (blue). The literature spectra were convoluted to our spectrograph resolution.

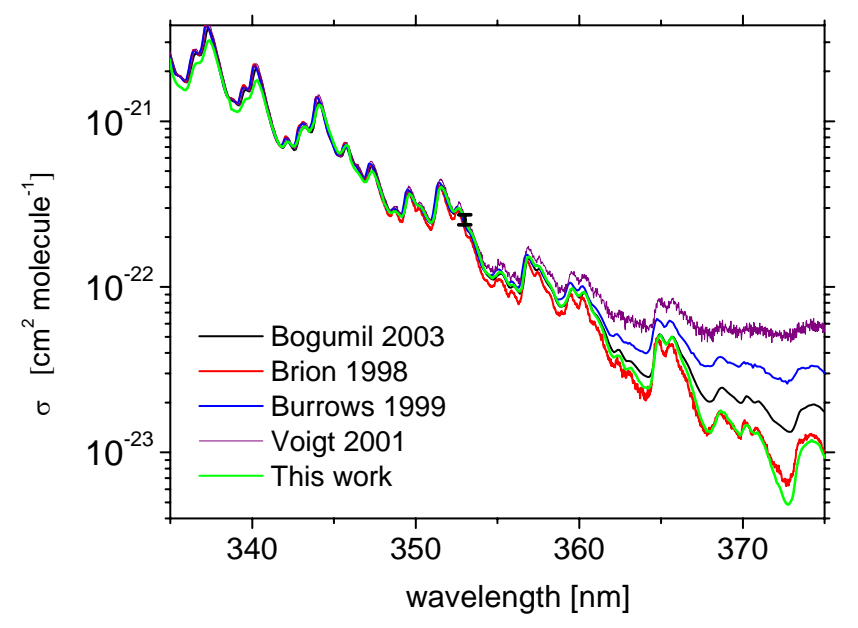

Fig. 5. $\mathrm{O}_{3}$ absorption cross-sections from this work and recent literature spectra (Voigt et al., 2001; Burrows et al., 1999; Bogumil et al., 2003; Brion et al., 1998). The standard deviation of literature cross-sections at $353 \mathrm{~nm}$ is indicated by an error bar.

\subsection{Ozone absorption}

In contrast to the $\mathrm{SO}_{2}$ absorption cross-sections, relatively poor agreement exists between reported cross-sections of $\mathrm{O}_{3}$ in the minimum between the Huggins and Chappuis bands (Bogumil et al., 2003; Burrows et al., 1999; Voigt et al., 2001; Brion et al., 1998). Although various workers report similar absorption features, the absorption cross-sections differ enormously around $370 \mathrm{~nm}$ (Fig. 5). Agreement above $360 \mathrm{~nm}$ is poor owing to the very weak absorption and the relatively modest concentrations of $\mathrm{O}_{3}$ in samples. With the long effective pathlength of our instrument, we report an improved estimate of ozone absorption cross-section in this region. 


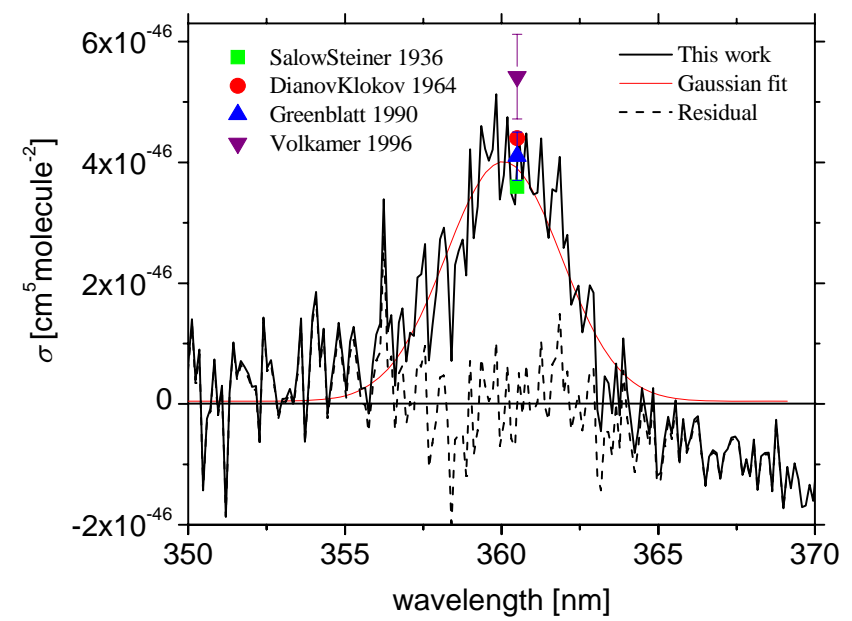

Fig. 6. Experimental spectrum (black) and Gaussian fit (red) of the collision-induced absorption of the $\mathrm{O}_{4}$ dimer. Literature maxima shown are those of Salow and Steiner (green square), Greenblatt (blue triangle), Dianov-Klokov (red circle), and Volkamer (purple triangle). To facilitate comparison with the literature maxima, our measured spectrum was shifted downwards by the offset of the Gaussian fit.

Intensity spectra of around $1 \% \mathrm{O}_{3}$ in $\mathrm{O}_{2}$ were recorded with a $5 \mathrm{~min}$ averaging time and at a resolution of $0.26 \mathrm{~nm}$. The ozone concentration in the cavity was quantified from the absorption at $320 \mathrm{~nm}$. The absorption cross-section and literature spectra are shown in Fig. 5. Of the literature spectra, Brion et al. (1998) and Voigt et al. (2001) employed FTS, while the data from Burrows et al. (1999) and from Bogumil et al. (2003) employed monochromators developed for satellite monitoring. The IBBCEAS spectrum was corrected for the weak collision-induced absorption of the $\mathrm{O}_{4}$ dimer at $360 \mathrm{~nm}$ (see below). (Note that the magnitude of the absorption cross-section at $353 \mathrm{~nm}$ is fixed to the average literature cross-section by the calibration of the mirror reflectivity.) Below $340 \mathrm{~nm}$, our cross-sections are 10 to $20 \%$ smaller than the literature values, probably because our mirror reflectivity is overestimated at short wavelengths. At longer wavelengths, the spectra diverge, with the IBBCEAS spectrum agreeing closely with the Brion spectrum. Remarkably little noise is apparent in the IBBCEAS spectrum, and linear absorption behaviour with concentration is apparent even at $370 \mathrm{~nm}$ where the absorption is weak (Fig. 2a). Hence the spectrum reported here provides good evidence that the $\mathrm{O}_{3}$ absorption in this region is even weaker than most previous reports suggest.
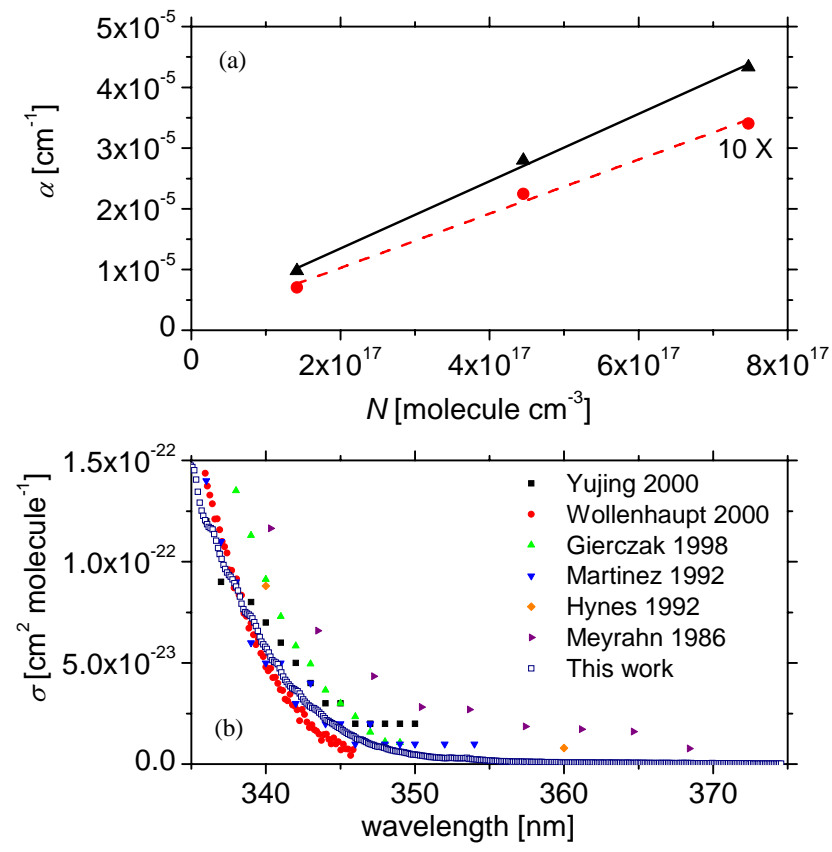

Fig. 7. (a) Dependence of absorption coefficient on the acetone concentration at $340 \mathrm{~nm}$ (black triangles) and at $350 \mathrm{~nm}$ (red circles). Correlation coefficients are 0.996 and 0.987 , respectively. (b) Acetone absorption cross-section of this work and of several literature spectra.

The collision-induced absorption of the $\mathrm{O}_{4} \operatorname{dimer}\left({ }^{1} \Sigma_{\mathrm{g}}^{+}+{ }^{1}\right.$ $\left.\Sigma_{\mathrm{g}}^{+}(v=1) \leftarrow{ }^{3} \Sigma_{\mathrm{g}}^{-}+{ }^{3} \Sigma_{\mathrm{g}}^{+}\right)$contributes marginally to the $\mathrm{O}_{3}$ absorption spectrum at $360.5 \mathrm{~nm}$. The cross-section of the dimer was determined by comparing the sample extinction of pure $\mathrm{O}_{2}$ versus that of $\mathrm{N}_{2}$. Differences between the Rayleigh scattering cross-sections of $\mathrm{N}_{2}$ and $\mathrm{O}_{2}$ are small and contribute only a small baseline offset to the extinction. The observed absorption feature was fitted to a Gaussian line shape on a sloping baseline (Fig. 6). The magnitude of the Gaussian maximum was $4.0 \times 10^{-46} \mathrm{~cm}^{5}$ molecule ${ }^{-2}$ at $360.1 \mathrm{~nm}$ with a FWHM of $4.3 \mathrm{~nm}$, within $9 \%$ of the average literature value for the $\mathrm{O}_{4}$ cross-section peak, and in satisfactory agreement with the careful measurements of Greenblatt and co-workers $\left(4.10 \times 10^{-46} \mathrm{~cm}^{5}\right.$ molecule ${ }^{-2}$ at $360.5 \mathrm{~nm}$ with a FWHM of $4.0 \mathrm{~nm}$ ) and other work (Greenblatt et al., 1990; Dianov-Klokov, 1964; Volkamer, 1996; Salow and Steiner, 1936). Nevertheless, our signal-to-noise ratio is small despite the relatively long effective pathlength of our system $\left(L_{\text {eff }}=d /(1-R) \approx 500 \mathrm{~m}\right)$ in pure $\mathrm{O}_{2}$ : the spectrum of Greenblatt taken at $55 \mathrm{~atm} \mathrm{O}_{2}$ is to be preferred to our results. More precise estimates of the absorption cross-section would be feasible with higher mirror reflectivities or at higher $\mathrm{O}_{2}$ pressures. 


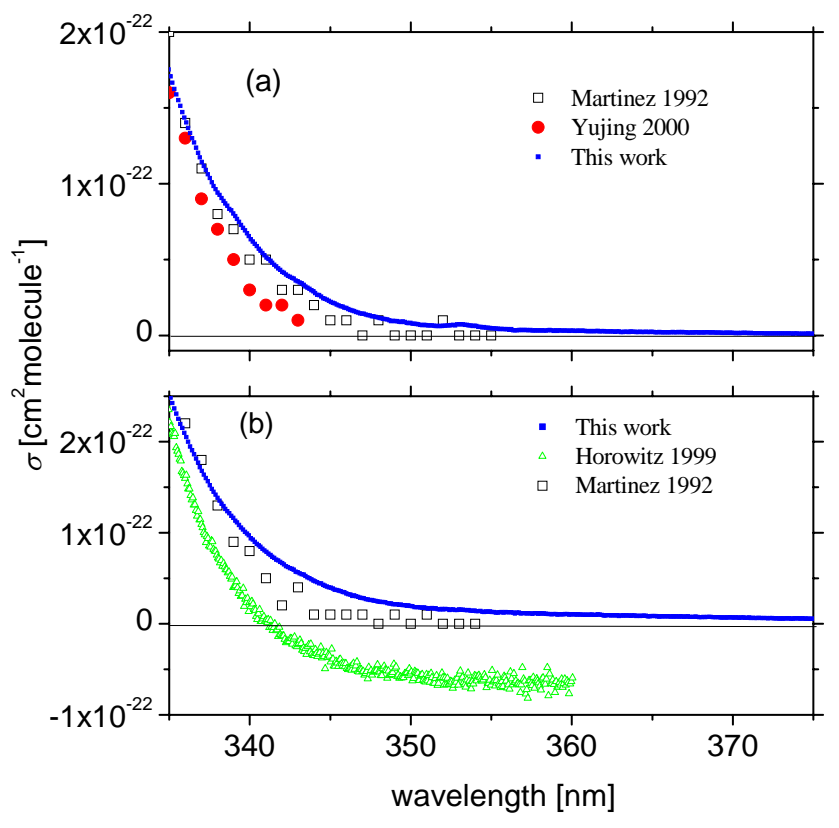

Fig. 8. Absorption cross-sections of (a) 2-butanone and (b) 2pentanone.

\subsection{Ketone spectra}

Spectra of acetone, 2-pentanone, and 2-butanone were measured from 335 to $355 \mathrm{~nm}$. The ketones were introduced via a $\mathrm{N}_{2}$ stream $\left(0.5 \mathrm{~L} \mathrm{~min}^{-1}\right)$ into the cavity and quantified from the literature absorption cross-sections at $320 \mathrm{~nm}$. The acetone cross-sections used were those of Gierczak et al. and the 2-pentanone and 2-butanone cross-sections were taken from Martinez and co-workers (Gierczak et al., 1998; Martinez et al., 1992). The acetone concentration was further diluted to check the linearity of the absorption measurement. The absorption of acetone increased linearly with concentration at $340 \mathrm{~nm}$ and $350 \mathrm{~nm}$, where the absorption differs by over an order of magnitude (Fig. 7a). For acetone, the absorption cross-section was derived from the slope of the linear regression of the three concentrations; Fig. $7 \mathrm{~b}$ shows the resulting spectrum reported to $355 \mathrm{~nm}$ (above which the correlation coefficient $R^{2}$ fell below 0.9 ). The lamp stability would increasingly influence the measurement of progressively weaker absorption at longer wavelengths.

The resulting absorption cross-section of acetone compares favourably with the available literature spectra. Most literature spectra are evidently close to their detection limits for such weak absorptions and agreement is poor even at the shortest wavelengths (largest absorption) in Fig. 7b. Of the spectra, those of Mu and Mellouki, Wollenhaupt, Martinez, and Gierczak exhibit the lowest discernable measurement noise (Mu and Mellouki, 2000; Wollenhaupt et al., 2000; Martinez et al., 1992; Gierczak et al., 1998). Our spectrum is in reasonable agreement with these spectra. At wavelengths shorter than $340 \mathrm{~nm}$ our measured absorption increases less strongly than other spectra, possibly indicating an overestimation of the mirror reflectivity at the short wavelength limit of the spectrometer. On the other hand, the linear dependence of the absorption with concentration at $340 \mathrm{~nm}$, and particularly at $350 \mathrm{~nm}$, provides strong evidence for the reliability of our cross-sections at these and similar wavelengths. Small undulations are visible in the IBBCEAS absorption spectra and probably correspond to the tail-end of small absorption structures that have been known for a long time (Noyes et al., 1956).

Spectra of 2-butanone and 2-pentanone are shown in Fig. 8. These spectra were determined from the absorption at a single concentration $\left(2.07 \times 10^{17}\right.$ molecule $\mathrm{cm}^{-3}$ for 2butanone and $1.05 \times 10^{17}$ molecule $\mathrm{cm}^{-3}$ for 2-pentanone). Cross-sections from this work agree with earlier spectra at the shortest wavelengths; again, lower noise is evident, especially at longer wavelengths. The spectrum of 2-butanone clearly agrees closely with that of Martinez and co-workers to $355 \mathrm{~nm}$. For 2-pentanone, the IBBCEAS spectrum is higher than either the spectrum of Martinez or that of Horowitz. In the case of Horowitz et al., the negative values probably signify some measurement artefact (Horowitz, 1999). In like manner, the IBBCEAS spectrum does not fall to zero at longer wavelengths (as would be expected); we ascribe this result to a small decrease in the lamp output over the duration of the measurement, thereby giving rise to an apparent absorption.

\subsection{Concentration measurement of $\mathrm{BrO}, \mathrm{Br}_{2}$, and $\mathrm{O}_{3}$}

With a broad spectral window, the concentrations of several species can be determined concurrently. We illustrate this application of the instrument by quantifying the composition of a sample comprising $\mathrm{Br}_{2}, \mathrm{O}_{3}$, and the short-lived species $\mathrm{BrO}$. $\mathrm{BrO}$ was produced inside the cavity at reduced pressures ( 3 to $18 \mathrm{mbar}$ ) by photolysing $\mathrm{Br}_{2}$ in the presence of $\mathrm{O}_{3}$ :

$\mathrm{Br}_{2}+h v \rightarrow \mathrm{Br}+\mathrm{Br}$
$\mathrm{O}_{3}+\mathrm{Br} \rightarrow \mathrm{BrO}+\mathrm{O}_{2}$

Molecular bromine, $\mathrm{Br}_{2}$, has a broad absorption band from 200 to $510 \mathrm{~nm}$ with a maximum at $420 \mathrm{~nm}$ and unity photolysis quantum efficiency (Atkinson et al., 2007). With filters placed behind the cavity, $\mathrm{Br}_{2}$ is readily photolysed by residual light in the cavity. Under these conditions BrO formation is prompt. Nevertheless, rapid self-reaction suppresses the $\mathrm{BrO}$ concentration in the cavity:

$\mathrm{BrO}+\mathrm{BrO} \rightarrow \mathrm{Br}_{2}+\mathrm{O}_{2}$

$\mathrm{BrO}+\mathrm{BrO} \rightarrow 2 \mathrm{Br}+\mathrm{O}_{2}$

$\mathrm{BrO}$ is readily identified by the $\mathrm{A}^{2} \prod_{3 / 2} \leftarrow \mathrm{X}^{2} \prod_{3 / 2}$ transition, with the $(7,0),(6,0),(5,0)$ and $(4,0)$ vibrational 


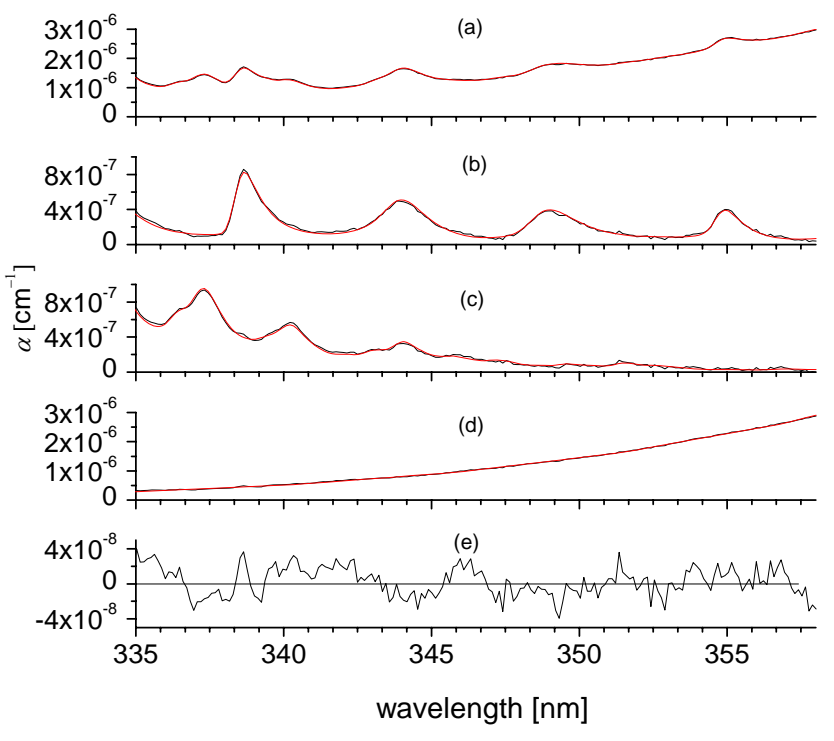

Fig. 9. Absorption and fitted spectra for the $\mathrm{Br}_{2}, \mathrm{O}_{3}$, and $\mathrm{BrO}$ system. (a) Measured spectrum (black) and fitted result (red). The individual components of the spectrum are (b) $\mathrm{BrO}$, (c) $\mathrm{O}_{3}$, and (d) $\mathrm{Br}_{2}$. (e) Residual of the fit.

bands falling within the spectral range of our spectrometer (Fig. 9b). The large absorption cross-section of this transition permits sensitive retrieval of even very low concentrations of BrO.

The number densities of $\mathrm{O}_{3}, \mathrm{Br}_{2}$, and $\mathrm{BrO}$ were retrieved by least squares fitting their literature cross-sections to the absorption coefficient and including a linear offset:

$\alpha(\lambda)=N_{\mathrm{BrO}} \sigma_{\mathrm{BrO}}(\lambda)+N_{\mathrm{O}_{3}} \sigma_{\mathrm{O}_{3}}(\lambda)+N_{\mathrm{Br}_{2}} \sigma_{\mathrm{Br}_{2}}(\lambda)+a+b \lambda(10)$

Literature cross-sections were those of Fleischman et al. (2004) for $\mathrm{BrO}$, the IUPAC recommendation for $\mathrm{Br}_{2}$ (Atkinson et al., 2007) and Voigt et al. (2001) for $\mathrm{O}_{3}$ and were convoluted with our instrument function. As the composition of the sample is probably non-uniform in the sample cell, we note that the fitted number densities represent pathlength-integrated concentrations or column densities. A typical absorption spectrum of the sample and fit of the literature spectra over the range $336 \mathrm{~nm}$ to $358 \mathrm{~nm}$ is shown in Fig. 9. The absorption features of $\mathrm{BrO}$ and $\mathrm{O}_{3}$ are readily evident against the monotonically increasing absorption of $\mathrm{Br}_{2}$ with wavelength. The fitted curve closely matches the experimental absorption and the residual is small (RMS of $\left.1.8 \times 10^{-8} \mathrm{~cm}^{-1}\right)$. The fitted concentration values were little affected by extending the fitting window to $370 \mathrm{~nm}$ (a maximum change of $8 \%$ was found for $N_{\mathrm{Br} 2}$ ). Excluding parameters $a$ and $b$ influenced the fit result more, with the value of $N_{\mathrm{Br} 2}$ decreasing by $31 \%$. In this case, $a$ and $b$ most likely compensate for a nominal offset in the absorption arising from a slow decline in the lamp intensity.

The concentration of $\mathrm{BrO}$ in the flow cell was explored as a function of reactant concentration (Fig. 10). The $\mathrm{O}_{3}$ concen-

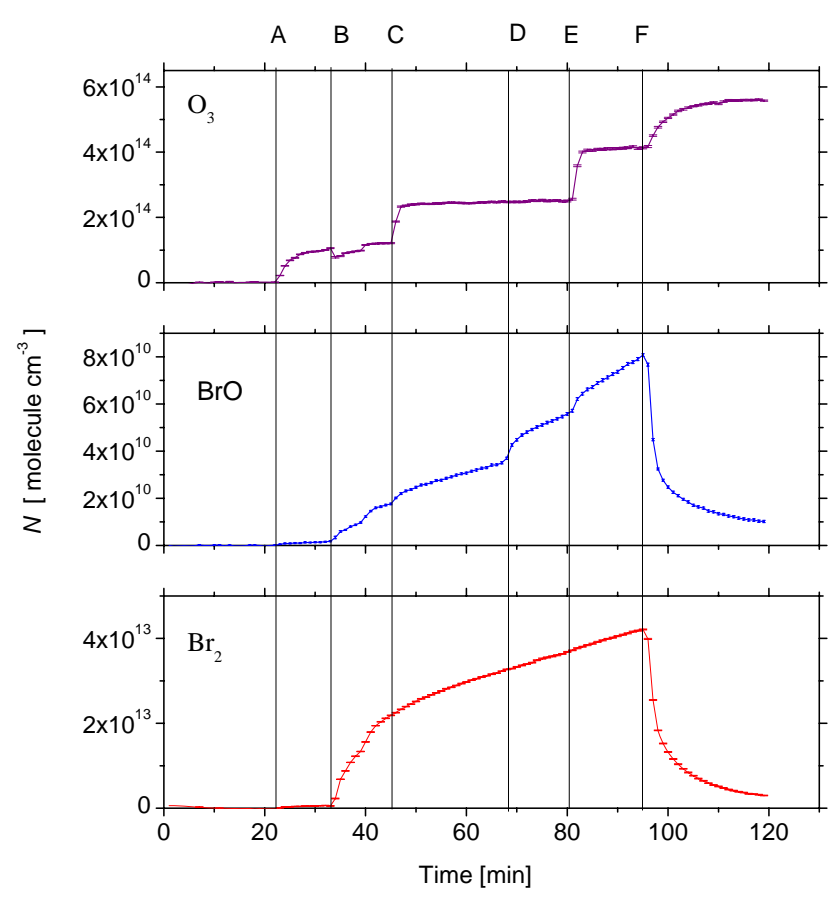

Fig. 10. Temporal dependence of the number density of $\mathrm{O}_{3}, \mathrm{BrO}$, and $\mathrm{Br}_{2}$ in the flow cell. Points $\mathrm{A}-\mathrm{F}$ indicate changes in either the input concentrations or photolysis rate.

tration in the input stream was increased at points $\mathrm{A}, \mathrm{C}$, and $\mathrm{E}$ by ramping up the $\mathrm{O}_{3}$ generator output. $\mathrm{Br}_{2}$ was introduced at time $B$ by flowing $\mathrm{N}_{2}$ over $\mathrm{Br}_{2}$ in a liquid nitrogen/alcohol cooling bath initially at $-30{ }^{\circ} \mathrm{C}$. As expected, photolysis of $\mathrm{Br}_{2}$ in the presence of $\mathrm{O}_{3}$ results in the immediate appearance of $\mathrm{BrO}$; the $\mathrm{BrO}$ concentration increases with both $\mathrm{Br}_{2}$ and $\mathrm{O}_{3}$ concentration. The temperature of the cooling bath rose about $10^{\circ} \mathrm{C}$ over the course of the experiment, causing a gradual rise in the $\mathrm{Br}_{2}$ and $\mathrm{BrO}$ concentrations. After the $\mathrm{Br}_{2}$ source was stopped at time $F$, both $\mathrm{Br}_{2}$ and $\mathrm{BrO}$ concentrations dropped off sharply, whereas the $\mathrm{O}_{3}$ concentration rose by about a third as $\mathrm{Br}$-catalysed $\mathrm{O}_{3}$ loss is progressively choked off. The $\mathrm{BrO}$ concentration also rose at time $D$, when the $\mathrm{Br}_{2}$ photolysis rate was increased by shining a high power $465 \mathrm{~nm}$ LED diagonally across the transparent centre of the flow tube.

The observed behaviour of the concentration of each species is in sensible agreement with known chemistry. Under stable inlet conditions, minimal scan-to-scan variation is observed. The precision of each concentration measurement was estimated based on the standard deviation from a seven-point running average between 49 and $65 \mathrm{~min}$. Values of $1.2 \times 10^{-12}, 4.5 \times 10^{-10}$, and $1.6 \times 10^{-8}$ molecules $\mathrm{cm}^{-3}$ were found for $\mathrm{O}_{3}, \mathrm{Br}_{2}$, and $\mathrm{BrO}$, respectively, which are comparable to the statistical uncertainties of the fit (respective averages of $2.1 \times 10^{-12}, 9.0 \times 10^{-10}$, and $4.3 \times$ $10^{-8}$ molecules $\mathrm{cm}^{-3}$ ). We note in passing that whereas our measurements were obtained under steady-state conditions 
with low $\mathrm{BrO}$ concentrations, previous $\mathrm{BrO}$ measurements have recorded the absorption of higher instantaneous $\mathrm{BrO}$ concentrations, either by using a microwave discharge or with short-time observations following flash lamp or laser photolysis of $\mathrm{Br}_{2}$ (Fleischmann et al., 2004; Wahner et al., 1988; Sander and Friedl, 1989; Basco and Dogra, 1971; Friedl and Sander, 1989; Gilles et al., 1997; Wilmouth et al., 1999; Laszlo et al., 1997; Cox et al., 1982; Orlando et al., 1991).

\section{Discussion}

The results above show the potential of the IBBCEAS system for retrieving weak absorption spectra in the near-UV at moderate resolution. The instrument performance is affected by several factors which we discuss below.

Whereas earlier near-UV IBBCEAS systems employed a $365 \mathrm{~nm}$ LED, in this study a Xe arc lamp was used as the light source. The high radiance of LEDs at $365 \mathrm{~nm}$ is attractive for monitoring several species over a narrow spectral window, but the spectral output falls rapidly from the maximum and has a typical FWHM of only about $10 \mathrm{~nm}$. High power LEDs are not yet available below $365 \mathrm{~nm}$. In contrast, the Xe arc-lamp spectrum is relatively unstructured in this spectral range and better suited to retrieving reference spectra. $\mathrm{Xe}$ arc lamps also have useful output at even shorter wavelengths and can be used for relatively broad spectral coverage (greater than $100 \mathrm{~nm}$ with appropriate cavity mirrors), which we have demonstrated in recent chamber studies of low volatility organic species (Chen et al., 2011). Notwithstanding these advantages, arc-lamps (and other very broadband sources) require stringent filtering to minimise stray light levels.

The sensitive absorption of this spectrometer (ca. $2 \times$ $10^{-8} \mathrm{~cm}^{-1}$ ) is with mirrors of only modest reflectivity. Although adequate for the purposes of this study, the sensitivity of the instrument could be improved with higher reflectivity mirrors. Higher reflectivity mirrors also lower the cavity transmission and the signal-to-noise ratio, so a balance must be struck between these competing factors. The reflectivity of the dielectric mirrors must be calibrated. In this study, we used a combination of the Rayleigh scattering and the wellestablished absorption of $\mathrm{O}_{3}$ at $353 \mathrm{~nm}$ to determine the overall reflectivity. The mirror reflectivity is mostly flat across the spectral window determined by the filters. Any uncertainty in the mirror reflectivity - or, more accurately, in the $(1-R)$ term in Eq. (1) - contributes linearly to the overall uncertainty in the absorption coefficient. In the results here, this uncertainty is 8 to $10 \%$ at $353 \mathrm{~nm}$ but increases towards the long and short-wavelength limits of the spectra owing to the uncertainty in the $(1-R)$ term. Below $340 \mathrm{~nm}$, our spectra were 10 to $20 \%$ lower than previously reported absorption cross-sections, suggesting that the mirror reflectivity was overestimated at the short wavelength limit and that our spectra are less accurate in this region. Taking the wavelength-dependence of the uncertainty into account, we estimate the uncertainty in our cross-sections above $340 \mathrm{~nm}$ to range from 10 to $15 \%$, which is acceptable for many applications and in line with the uncertainty in prior IBBCEAS studies. This work has also demonstrated that transmission of the windows outside of the high reflectivity range can be exploited to quantify components of the sample based on absorption in other spectral regions. In the results above, the small uncertainty of the (larger) absorption cross-sections of $\mathrm{O}_{3}$ and ketones allows direct in situ quantification of these species. Sample losses elsewhere in the system can therefore be ignored.

In comparison to numerous literature spectra, the IBBCEAS spectra have significantly lower noise and also display linear absorption behaviour for weak absorptions. In these regions, where large variations between literature data are found, we believe that the spectra reported here are to be preferred to most prior spectra. Two caveats are in order, however. Firstly, even with long effective pathlengths, lamp intensity variations and gradual lamp dimming gives rise to apparent weak absorptions. This is evident in the small positive offset in the length wavelength limit of the 2-pentanone spectrum and implicitly in the linear offset of the fitting parameters of the $\mathrm{BrO}, \mathrm{O}_{3}$, and $\mathrm{Br}_{2}$ spectrum. Secondly, the accuracy of the absorption measurement tends to be worse at the limits of the high reflectivity region of the cavity mirrors, as we observe below $340 \mathrm{~nm}$.

\section{Conclusions}

A near-UV IBBCEAS instrument has been developed for measuring weak absorption spectra from 335 to $375 \mathrm{~nm}$. Spectra of $\mathrm{SO}_{2}$ measured with the instrument show good agreement with literature spectra. The instrument has been used to retrieve revised absorption cross-sections of $\mathrm{O}_{3}$, acetone, 2-butanone, and 2-pentanone, for which previously reported values diverge widely. The IBBCEAS spectra showed linear absorption behaviour and low spectral noise and provide revised estimates for the long-wavelength tail of these spectra. Concurrent retrieval of the concentrations of $\mathrm{BrO}$, $\mathrm{Br}_{2}$, and $\mathrm{O}_{3}$ in a steady-state flow system has been demonstrated.

Acknowledgements. The authors thank Andy Ruth for loan of the dielectric mirrors and other optical components. We are also grateful to the physics workshop for their assistance with this project, and to Steven Darby for helping with the paper preparation. This work was supported by Science Foundation Ireland (06/RFP/CHP055) and through the EU FP7 project EUROCHAMP2 (grant no. 228335).

Edited by: A. Hofzumahaus 


\section{References}

Atkinson, R., Baulch, D. L., Cox, R. A., Crowley, J. N., Hampson, R. F., Hynes, R. G., Jenkin, M. E., Rossi, M. J., and Troe, J.: Evaluated kinetic and photochemical data for atmospheric chemistry: Volume III - gas phase reactions of inorganic halogens, Atmos. Chem. Phys., 7, 981-1191, doi:10.5194/acp-7-981-2007, 2007.

Ball, S. M., Hollingsworth, A. M., Humbles, J., Leblanc, C., Potin, P., and McFiggans, G.: Spectroscopic studies of molecular iodine emitted into the gas phase by seaweed, Atmos. Chem. Phys., 10, 6237-6254, doi:10.5194/acp-10-6237-2010, 2010.

Basco, N. and Dogra, S. K.: Reactions of halogen oxides studied by flash photolysis .3. production and reactions of $\mathrm{BrO}$ and $\mathrm{ClO}$ radicals in halogen-sensitized decomposition of chlorine dioxide, Proceedings of the Royal Society of London Series AMathematical and Physical Sciences, 323, 417, 1971.

Bobrowski, N., Kern, C., Platt, U., Hörmann, C., and Wagner, T.: Novel $\mathrm{SO}_{2}$ spectral evaluation scheme using the 360 $390 \mathrm{~nm}$ wavelength range, Atmos. Meas. Tech., 3, 879-891, doi:10.5194/amt-3-879-2010, 2010.

Bogumil, K., Orphal, J., Homann, T., Voigt, S., Spietz, P., Fleischmann, O. C., Vogel, A., Hartmann, M., Kromminga, H., Bovensmann, H., Frerick, J., and Burrows, J. P.: Measurements of molecular absorption spectra with the SCIAMACHY preflight model: instrument characterization and reference data for atmospheric remote-sensing in the $230-2380 \mathrm{~nm}$ region, Journal of Photochemistry and Photobiology A-Chemistry, 157, 167184, 2003.

Brion, J., Chakir, A., Charbonnier, J., Daumont, D., Parisse, C., and Malicet, J.: Absorption spectra measurements for the ozone molecule in the 350-830 nm region, J. Atmos. Chem., 30, 291299, 1998.

Burrows, J. P., Richter, A., Dehn, A., Deters, B., Himmelmann, S., and Orphal, J.: Atmospheric remote-sensing reference data from GOME - 2. Temperature-dependent absorption cross sections of $\mathrm{O}_{3}$ in the 231-794 nm range, J. Quant. Spectr. Radiat. T., 61, 509-517, 1999.

Chen, J., Wenger, J. C., and Venables, D. S.: Absorption cross-sections of nitrophenols and organic nitrites in the nearultraviolet, in preparation, 2011.

Cox, R. A., Sheppard, D. W., and Stevens, M. P.: Absorptioncoefficients and kinetics of the BrO radical using molecular modulation, J. Photochemistry, 19, 189-207, 1982.

Dianov-Klokov, V. I.: Absorption spectrum of oxygen at pressues from 2 to $35 \mathrm{~atm}$ in the region from 12600 to $3600 \AA$, Opt. Spectrosc., 16, 224-227, 1964.

Dixneuf, S., Ruth, A. A., Vaughan, S., Varma, R. M., and Orphal, J.: The time dependence of molecular iodine emission from Laminaria digitata, Atmos. Chem. Phys., 9, 823-829, doi:10.5194/acp-9-823-2009, 2009.

Dorn, H.-P., Apodaca, R. L., Ball, S. M., Brauers, T., Brown, S. S., Cohen, R. C., Crowley, J. N., Dubé, W. P., Fry, J. L., Fuchs, H., Häseler, R., Heitmann, U., Jones, R. L., Kato, S., Kajii, Y., Kiendler-Scharr, A., Labazan, I., Langridge, J. M., Matsumoto, J., Meinen, J., Nishida, S., Platt, U., Pöhler, D., Rohrer, F., Rollins, A. W., Ruth, A. A., Schlosser, E., Schuster, G., Shillings, A. J. L., Simpson, W. R., Thieser, J., Venables, D. S., Wahner, A., Wegener, R., and Wooldridge, P. J.: Intercomparison of NO3 radical detection instruments in the Atmosphere Simulation
Chamber SAPHIR, Atmos. Chem. Phys. Discuss., in preparation, 2011.

Fiedler, S. E., Hese, A., and Ruth, A. A.: Incoherent broad-band cavity-enhanced absorption spectroscopy, Chem. Phys. Lett., 371, 284-294, 2003.

Fiedler, S. E., Hese, A., and Heitmann, U.: Influence of the cavity parameters on the output intensity in incoherent broadband cavity-enhanced absorption spectroscopy, Review of Scientific Instruments, 78, 073104, doi:10.1063/1.2752608, 2007.

Fleischmann, O. C., Hartmann, M., Burrows, J. P., and Orphal, J.: New ultraviolet absorption cross-sections of $\mathrm{BrO}$ at atmospheric temperatures measured by time-windowing Fourier transform spectroscopy, J. Photochem. Photobiol. A-Chemistry, 168, 117132, 2004.

Friedl, R. R. and Sander, S. P.: Kinetics and product studies of the reaction $\mathrm{ClO}+\mathrm{BrO}$ using discharge-flow mass-spectrometry, J. Phys. Chem., 93, 4756-4764, 1989.

Fuchs, H., Ball, S. M., Bohn, B., Brauers, T., Cohen, R. C., Dorn, H.-P., Dubé, W. P., Fry, J. L., Häseler, R., Heitmann, U., Jones, R. L., Kleffmann, J., Mentel, T. F., Müsgen, P., Rohrer, F., Rollins, A. W., Ruth, A. A., Kiendler-Scharr, A., Schlosser, E., Shillings, A. J. L., Tillmann, R., Varma, R. M., Venables, D. S., Villena Tapia, G., Wahner, A., Wegener, R., Wooldridge, P. J., and Brown, S. S.: Intercomparison of measurements of $\mathrm{NO}_{2}$ concentrations in the atmosphere simulation chamber SAPHIR during the NO3Comp campaign, Atmos. Meas. Tech., 3, 21-37, doi:10.5194/amt-3-21-2010, 2010.

Gherman, T., Venables, D. S., Vaughan, S., Orphal, J., and Ruth, A. A.: Incoherent broadband cavity-enhanced absorption spectroscopy in the near-ultraviolet: Application to HONO and NO2, Environ. Sci. Technol., 42, 890-895, 2008.

Gierczak, T., Burkholder, J. B., Bauerle, S., and Ravishankara, A. R.: Photochemistry of acetone under tropospheric conditions, Chemical Physics, 231, 229-244, 1998.

Gilles, M. K., Turnipseed, A. A., Burkholder, J. B., Ravishankara, A. R., and Solomon, S.: Kinetics of the IO radical .2. Reaction of IO with BrO, J. Phys. Chem. A, 101, 5526-5534, 1997.

Greenblatt, G. D., Orlando, J. J., Burkholder, J. B., and Ravishankara, A. R.: Absorption Measurements of Oxygen Between 330 and 1140 nm, J. Geophys. Res., 95, 18577-18582, 1990.

Honninger, G. and Platt, U.: Observations of $\mathrm{BrO}$ and its vertical distribution during surface ozone depletion at Alert, Atmos. Environ., 36, 2481-2489, 2002.

Horowitz, A.: Absorption cross sections of 2-pentanone, 3pentanone, and 3-hexanone, Personal communication of unpublished data of the Max-Planck-Institut für Chemie, Mainz, 1999.

Hynes, A. J., Kenyon, E. A., Pounds, A. J., and Wine, P. H.: Temperature-dependent absorption cross-sections for acetone and n-butanone-implications for atmospheric lifetimes, Spectrochim. Acta A, 48, 1235-1242, 1992.

Laszlo, B., Huie, R. E., Kurylo, M. J., and Miziolek, A. W.: Kinetic studies of the reactions of BrO and IO radicals, J. Geophys. Res.Atmos., 102, 1523-1532, 1997.

Mahajan, A. S., Oetjen, H., Lee, J. D., Saiz-Lopez, A., McFiggans, G. B., and Plane, J. M. C.: High bromine oxide concentrations in the semi-polluted boundary layer, Atmos. Environ., 43, 38113818, 2009.

Martinez, R. D., Buitrago, A. A., Howell, N. W., Hearn, C. H., and Joens, J. A.: The near UV absorption-spectra of several aliphatic- 
aldehydes and ketones at 300-K, Atmospheric Environment Part a-General Topics, 26, 785-792, 1992.

Mazurenka, M., Orr-Ewing, A. J., Peverall, R., and Ritchie, G. A. D.: Cavity ring-down and cavity enhanced spectroscopy using diode lasers, Annual Reports Section C, 101, 100-142, 2005.

Meyrahn, H., Pauly, J., Schneider, W., and Warneck, P.: Quantum yields for the photodissociation of acetone in air and an estimate for the lifetime of acetone in the lower troposphere, J. Atmos. Chem., 4, 277-291, 1986.

$\mathrm{Mu}, \mathrm{Y}$. J. and Mellouki, A.: The near-UV absorption cross sections for several ketones, J. Photochem. Photobiol. A-Chemistry, 134, 31-36, 2000.

Naus, H. and Ubachs, W.: Experimental verification of Rayleigh scattering cross sections, Optics Lett., 25, 347-349, 2000.

Noyes, W. A., Porter, G. B., and Jolley, J. E.: The Primary Photochemical Process in Simple Ketones, Chem. Rev., 56, 49-94, 1956.

Orlando, J. J., Burkholder, J. B., Bopegedera, A. M. R. P., and Howard, C. J.: Infrared measurements of $\mathrm{BrO}\left(\mathrm{X}^{2} \Pi_{3 / 2}\right)$, J. Molecular Spectr., 145, 278-289, 1991.

Peters, C., Pechtl, S., Stutz, J., Hebestreit, K., Hönninger, G., Heumann, K. G., Schwarz, A., Winterlik, J., and Platt, U.: Reactive and organic halogen species in three different European coastal environments, Atmos. Chem. Phys., 5, 3357-3375, doi:10.5194/acp-5-3357-2005, 2005.

Salow, H. and Steiner, W.: Die durch Wechselwirkungskräfte bedingten Absorptionsspektra des Sauerstoffes, I. Die Absorptionsbanden des (O2-O2) Moleküls, Z. Physik, 99, 137-158, 1936.

Sander, S. P. and Friedl, R. R.: Kinetics and product studies of the reaction $\mathrm{ClO}+\mathrm{BrO}$ using flash photolysis-ultraviolet absorption, J. Phys. Chem., 93, 4764-4771, 1989.

Sneep, M. and Ubachs, W.: Direct measurement of the Rayleigh scattering cross section in various gases, J. Quant. Spectr. Radiat. T., 92, 293-310, 2005.

Steyert, D. W., Sirota, J. M., Mickelson, M. E., and Reuter, D. C.: Two new long-pass cells for infrared and visible spectroscopy, Rev. Scientific Instruments, 72, 4337-4343, 2001.

Sutton, J. A. and Driscoll, J. F.: Rayleigh scattering cross sections of combustion species at 266,355 , and $532 \mathrm{~nm}$ for thermometry applications, Optics Lett., 29, 2620-2622, 2004.

Thalman, R. and Volkamer, R.: Inherent calibration of a blue LED-CE-DOAS instrument to measure iodine oxide, glyoxal, methyl glyoxal, nitrogen dioxide, water vapour and aerosol extinction in open cavity mode, Atmos. Meas. Tech., 3, 1797-1814, doi:10.5194/amt-3-1797-2010, 2010.

Vandaele, A. C., Hermans, C., and Fally, S.: Fourier transform measurements of $\mathrm{SO}_{2}$ absorption cross sections: II. Temperature dependence in the $29000-44000 \mathrm{~cm}(-1)(227-345 \mathrm{~nm})$ region, J. Quant. Spectr. Radiat. T., 110, 2115-2126, 2009.
Varma, R. M., Venables, D. S., Ruth, A. A., Heitmann, U., Schlosser, E., and Dixneuf, S.: Long optical cavities for openpath monitoring of atmospheric trace gases and aerosol extinction, Appl. Optics, 48, B159-B171, 2009.

Venables, D. S., Gherman, T., Orphal, J., Wenger, J. C., and Ruth, A. A.: High sensitivity in situ monitoring of NO3 in an atmospheric simulation chamber using incoherent broadband cavityenhanced absorption spectroscopy, Environ. Sci. Technol., 40, 6758-6763, 2006.

Voigt, S., Orphal, J., Bogumil, K., and Burrows, J. P.: The temperature dependence (203-293 K) of the absorption cross sections of $\mathrm{O}_{3}$ in the $230-850 \mathrm{~nm}$ region measured by Fourier-transform spectroscopy, J. Photochem. Photobiol. A-Chemistry, 143, 1-9, 2001.

Volkamer, R.: Absorption von Sauerstoff im Herzberg I System und Anwendungen auf die Aromatenmessungen am EUropran PHOto REactor (EUPHORE), Diploma thesis, Univ. of Heidelberg, Germany, 1996.

Wagner, T., Ibrahim, O., Sinreich, R., Frieß, U., von Glasow, R., and Platt, U.: Enhanced tropospheric BrO over Antarctic sea ice in mid winter observed by MAX-DOAS on board the research vessel Polarstern, Atmos. Chem. Phys., 7, 3129-3142, doi:10.5194/acp-7-3129-2007, 2007.

Wahner, A., Ravishankara, A. R., Sander, S. P., and Friedl, R. R.: Absorption cross section of BrO between 312 and $385 \mathrm{~nm}$ at 298 and $223 \mathrm{~K}$, Chem. Phys. Lett., 152, 507-512, 1988.

Washenfelder, R. A., Langford, A. O., Fuchs, H., and Brown, S. S.: Measurement of glyoxal using an incoherent broadband cavity enhanced absorption spectrometer, Atmos. Chem. Phys., 8, 7779-7793, doi:10.5194/acp-8-7779-2008, 2008.

Wilmouth, D. M., Hanisco, T. F., Donahue, N. M., and Anderson, J. G.: Fourier transform ultraviolet spectroscopy of the A (2) $\mathrm{Pi}(3 / 2)$ $<-$ X (II3/2)-I-2 transition of BrO, J. Phys. Chem. A, 103, 89358945, 1999.

Wollenhaupt, M., Carl, S. A., Horowitz, A., and Crowley, J. N.: Rate coefficients for reaction of $\mathrm{OH}$ with acetone between 202 and 395 K, J. Phys. Chem. A, 104, 2695-2705, 2000.

Wu, T., Zhao, W. X., Li, J. S., Zhang, W. J., Chen, W. D., and Gao, X. M.: Incoherent Broadband Cavity Enhanced Absorption Spectroscopy Based on LED, Spectroscopy and Spectral Analysis, 28, 2469-2472, 2008.

Xiang, B., Zhu, C. Z., and Zhu, L.: Gas-phase absorption cross sections of 2-nitrobenzaldehyde and benzaldehyde in the 285$400 \mathrm{~nm}$ region, and photolysis of 2-nitrobenzaldehyde vapor at 308 and 351 nm, Chem. Phys. Lett., 474, 74-78, 2009. 